\title{
Cycling Exercise Classes May Be Bad for Your (Hearing) Health
}

\section{Citation}

Sinha, Sumi. 2017. Cycling Exercise Classes May Be Bad for Your (Hearing) Health. Doctoral dissertation, Harvard Medical School.

\section{Permanent link}

http://nrs.harvard.edu/urn-3:HUL.InstRepos:40620297

\section{Terms of Use}

This article was downloaded from Harvard University's DASH repository, and is made available under the terms and conditions applicable to Other Posted Material, as set forth at http:// nrs.harvard.edu/urn-3:HUL.InstRepos:dash.current.terms-of-use\#LAA

\section{Share Your Story}

The Harvard community has made this article openly available.

Please share how this access benefits you. Submit a story.

\section{Accessibility}




\section{Title Page}

Scholarly Report submitted in partial fulfillment of the MD Degree at Harvard Medical School

Date: 23 November, 2016

Student Name: Sumi Sinha, BS

Scholarly Report Title: Cycling Exercise Classes May Be Bad for Your (Hearing) Health

\section{Mentor Name(s) and Affiliations:}

Elliot D. Kozin, MD, Department of Otolaryngology, Massachusetts Eye and Ear Infirmary

Aaron K. Remenschneider, Department of Otolaryngology, Massachusetts Eye and Ear Infirmary

\section{Collaborators, with Affiliations:}

Matthew R. Naunheim, M.D., M.B.A., ${ }^{1}$ Samuel R. Barber, M.S., ${ }^{1}$ Kevin Wong, B.A., ${ }^{1}$ Leanna W. Katz, M.S.O.T., ${ }^{2}$ Ishmael J. M. Stefanov-Wagner, B.S., ${ }^{1}$ Aaron K.

Remenschneider, M.D. ${ }^{1}$

${ }^{1}$ Department of Otolaryngology, Massachusetts Eye and Ear Infirmary, Boston, MA, USA

${ }^{2}$ Department of Occupational Therapy, Spaulding Rehabilitation Hospital, Charlestown, MA, USA 
Abstract:

Objective: 1) Determine feasibility of smart phone-based mobile technology to measure noise exposure; and 2) measure noise exposure in exercise spin classes.

Study Design / Methods: The SoundMeter Pro App (Faber Acoustical) was installed and calibrated on iPhone and iPod devices in an audiology chamber using an external sound level meter to within $2 \mathrm{dBA}$ of accuracy. Recording devices were placed adjacent to participants attending spin classes in Boston, MA $(n=17)$ and used to measure sound level (A-weighted) and noise dosimetry during exercise according to National Institute for Occupational Safety and health (NIOSH) guidelines.

Results: The average length of exposure was $48.9 \pm 1.2$ (standard error of the mean [SEM]) minutes per class. Maximum sound recorded among 17 random classes was 116.7 dB, which was below the NIOSH instantaneous exposure guideline of $140 \mathrm{dBA}$. An average of $31.6 \pm 3.8$ minutes were spent over $100 \mathrm{dBA}$. This exceeds NIOSH recommendations of 15 minutes of exposure or less at $100 \mathrm{dBA}$ per day. Average noise exposure for one 45 -minute class was $8.95 \pm 1.2$ times the recommended noise exposure dose for an 8-hour workday.

Conclusion: Randomly sampled cycling classes demonstrated high noise levels and potential for noise induced hearing loss. Mobile dosimetry technology may enable users to self-monitor risk to their hearing and actively engage in noise protection measures. 


\section{Scholar Project Summary:}

The project detailed here was a prospective analysis of auditory toxicity in the spin class setting. The work was based on observations of hearing strain in spin classes. Previous work concerning auditory health in gym classes has been completed. Here we additionally used a readily accessible platform of iPhone noise dosimetry for data collection.

Design: The initial idea came from author LWK who observed the loud music played in spin classes. In consultation with authors LWK, EDK and AKR, we outlined a project that would test the hypothesis that spin classes could be toxic to hearing health. I did initial literature review to identify three iPhone apps that could be used for noise dosimetry. Based on the literature and on my beta testing, I identified one to be used in our study. With the assistance of the app developer and author IJMSW, I devised a methodology for calibrating and recording noise levels in open settings.

Execution: I completed the initial data collection to assess the feasibility of sound monitoring and for quality assurance. I then wrote a manual for the app use. Authors MRN, SRB, TO, and KW additionally assisted in data collection.

Analysis: I completed the data analysis for this project using Excel. I compared our findings to published literature to verify our methodology and findings. The data was presented to and discussed with authors EDK and AKR early in the project with multiple rounds of suggestions for improved data collection and analysis.

Writing: The published manuscript was initially drafted by myself. All authors participated in editing and revision of the manuscript. In particular, KW assisted in 
literature review and EDK and AKR completed substantial revisions of the throughout the process.

Publication citation: Sinha S, Kozin ED, Naunheim MR, Barber SR, Wong K, Katz LW, et al. Cycling exercise classes may be bad for your (hearing) health. The Laryngoscope. 2016 Oct12. [epub in advance of print]

PMID: 27731901

DOI: 10.1002/lary.26331 


\title{
Cycling Exercise Classes May Be Bad for Your (Hearing) Health
}

\author{
Sumi Sinha, BS; Elliott D. Kozin, MD; Matthew R. Naunheim, MD, MBA; Samuel R. Barber, MS; \\ Kevin Wong, BA; Leanna W. Katz, MSOT; Tiffany M. N. Otero, BS; Ishmael J. M. Stefanov-Wagner, BS; \\ Aaron K. Remenschneider, MD, MPH
}

Objectives/Hypothesis: 1) Determine feasibility of smartphone-based mobile technology to measure noise exposure; and 2) measure noise exposure in exercise spin classes.

Study Design: Observational Study.

Methods: The SoundMeter Pro app (Faber Acoustical, Salt Lake City, UT) was installed and calibrated on iPhone and iPod devices in an audiology chamber using an external sound level meter to within 2 dBA of accuracy. Recording devices were placed in the bike cupholders of participants attending spin classes in Boston, Massachusetts (n = 17) and used to measure sound level (A-weighted) and noise dosimetry during exercise according to National Institute for Occupational Safety and Health (NIOSH) guidelines.

Results: The average length of exposure was $48.9 \pm 1.2$ (standard error of the mean) minutes per class. Maximum sound recorded among 17 random classes was $116.7 \mathrm{dBA}$, which was below the NIOSH instantaneous exposure guideline of $140 \mathrm{dBA}$. An average of $31.6 \pm 3.8$ minutes were spent at $>100 \mathrm{dBA}$. This exceeds NIOSH recommendations of 15 minutes of exposure or less at $100 \mathrm{dBA}$ per day. Average noise exposure for one 45-minute class was $8.95 \pm 1.2$ times the recommended noise exposure dose for an 8-hour workday.

Conclusions: Preliminary data shows that randomly sampled cycling classes may have high noise levels with a potential for noise-induced hearing loss. Mobile dosimetry technology may enable users to self-monitor risk to their hearing and actively engage in noise protection measures.

Key Words: Exercise spin class, cycling, noise-induced hearing loss, mobile phone technology, noise exposure, noise dosimetry.

Level of Evidence: NA

Laryngoscope, 00:000-000, 2016

\section{INTRODUCTION}

Specialized indoor cycling or "spin" classes have emerged as a popular form of exercise. ${ }^{1}$ Thousands of participants now attend classes at cycling chains nationwide, attracted by the purported health benefits of this style of exercise. Such classes, however, regularly employ loud music played through speakers to set the pace and energy level for participants. ${ }^{1,2}$

Studies have shown that exercise physiology may make the auditory system more vulnerable to noise-induced

From the Department of Otolaryngology, Massachusetts Eye and Ear Infirmary, Boston (s.S., E.D.K., M.R.N., S.R.B., K.W., I.J.M.S.-w., A.K.R.); Department of Occupational Therapy, Spaulding Rehabilitation Hospital, Charlestown (L.w.K.); and Department of Anesthesia, Critical Care, and Pain Medicine, Massachusetts General Hospital, Boston (т.M.N.o.), Massachusetts, U.S.A.

Editor's Note: This Manuscript was accepted for publication August 26, 2016.

Presented at the Triological Society 119th Annual Meeting at the Combined Otolaryngology Spring Meetings, Chicago, Illinois, U.S.A., May 20-21, 2016.

S.S. and E.D.K. contributed equally to this work.

SoundMeter Pro app was donated by Faber Acoustical for purposes of study.

The authors have no other funding, financial relationships, or conflicts of interest to disclose.

Send correspondence to Elliott D. Kozin, MD, Massachusetts Eye and Ear Infirmary, 243 Charles Street, Boston, MA 02114.

E-mail: Elliott_Kozin@meei.harvard.edu

DOI: 10.1002/lary.26331 temporary threshold shifts (NITTS). ${ }^{3}$ The physiology of this heightened sensitivity during exercise is yet unproven, but it has been hypothesized that changes in metabolic activity (increased body temperature and release of catecholamines) and/or depressed stapedius muscle reflexes may permit a higher level of noise-induced damage during strenuous activity as compared to at rest. ${ }^{4}$ NITTS may in turn result in permanent damage to hearing health due to cochlear nerve degeneration. ${ }^{5}$ Taken together, the high noise exposure in cycling classes and the heightened vulnerability of the auditory system during exercise put class participants and instructors at risk for noise-induced hearing loss (NIHL).

Previous studies have shown that noise exposure in the setting of exercise gym classes can reach levels that may be toxic to the auditory system, ${ }^{6}$ including a study demonstrating NITTS in volunteers attending aerobics classes. ${ }^{7}$ Thus far, such work has required bulky and expensive equipment and was performed from the vantage point of gym owners, who routinely use loud music to create an atmosphere conducive to exercise for participants. Advances in mobile technology now allow consumers to access phone apps to monitor sound level and check noise dosimetry at low cost.

Taken together, we aim to 1) investigate the use of readily accessible smartphone technology to measure personal noise exposure, and 2) assess the risk of NIHL caused by the loud environments in recently popularized exercise cycling classes. 


\section{MATERIALS AND METHODS}

\section{Data Collection}

Study approval was obtained from the institutional review board of the Massachusetts Eye and Ear Infirmary. Noise exposure was quantified using the SoundMeter Pro for Apple iOS (Faber Acoustical, Salt Lake City, UT; versions 4.3.1 and 8.2). The native microphones of three devices were used for sound level recordings: iPhone 5 (iOS9), iPhone 6 (iOS9), and iPod Touch 6 (iOS9) (Apple, Cupertino, CA). Once installed on the appropriate device, microphone calibration was verified with an external sound meter using a pure tone in a soundproof chamber ( $\pm 2 \mathrm{~dB}$ accuracy). To measure noise exposure, instructorbased cycling classes $(n=17)$ were randomly attended at six different studios in Boston, Massachusetts. In each class, instructors played customized music playlists that varied in tempo and volume, based on exercise intensity. Class participants included authors (s.S., M.R.N., T.M.N.O., and K.w.) who were not blinded to the purposes of this study. Participants measured each sequential class attended and were instructed to sit near the center of the classroom when possible. Spin classes typically require registration prior to attendance, and bike selection was subject to availability. Thus, seat assignment was nonsystematically random. Microphones were placed in the bike cupholders with the microphones oriented outward. Speaker placement relative to seat location varied and was not recorded.

\section{Data Analysis}

Sound level (A-weighted, fast response) and dosimetry measurements were recorded on the SoundMeter Pro app at a frequency of 0.1 seconds. Sound recordings began when the class music started or when the first instructions were given. Sound recordings were stopped after the "cool-down" period of spin classes when music is typically lowered but not turned off.

National Institute for Occupational Safety and Health (NIOSH) guidelines were used to calculate class exposure dose and time-weighted averages (see Table I). ${ }^{8}$ NIOSH guidelines for noise exposure permit 8 hours of exposure at $85 \mathrm{dBA}$ in 1 day to safely prevent NIHL. ${ }^{8,9}$ For every 3 -dBA increase in exposure level, the permissible exposure limit is reduced by half. In this algorithm, exposure at $91 \mathrm{dBA}$ is permitted for 2 hours in a day, whereas 100-dBA exposure should not exceed 15 minutes in a day. Furthermore, if 8 hours of exposure at 85 $\mathrm{dBA}$ constitutes the maximum daily recommendation for noise exposure (100\% daily dose), the exposure dose is doubled for every 3 -dBA increase in noise level (i.e., 8 hours of exposure at

TABLE I.

National Institute for Occupational Safety and Health Noise Exposure Thresholds.

\begin{tabular}{llr}
\hline Exposure Level, dBA & PEL, hr & Exposure Dose* \\
\hline 85 & 8 & $100 \%$ \\
88 & 4 & $200 \%$ \\
91 & 2 & $400 \%$ \\
94 & 1 & $800 \%$ \\
97 & 0.5 & $1,600 \%$ \\
100 & 0.25 & $3,200 \%$ \\
103 & 0.125 & $6,400 \%$ \\
106 & 0.0625 & $12,800 \%$ \\
\hline \hline
\end{tabular}

${ }^{*}$ Based on 8-hour continuous exposure at noise level.

$\mathrm{PEL}=$ permissible exposure limit.

\begin{tabular}{lc}
\hline \multicolumn{2}{c}{ TABLE II. } \\
Summary of Sound Levels. \\
\hline Measure & Value \\
\hline Number of classes & 17 \\
Average sound level, dBA & $100.8 \pm 1.8$ \\
Highest sound level, dBA & 116.7 \\
$\begin{array}{l}\text { Average maximum sound } \\
\text { level recorded, dBA }\end{array}$ & $113.1 \pm 1.5$ \\
$\begin{array}{l}\text { Average time spent at }>100 \mathrm{~dB} \\
\text { sound level, min }\end{array}$ & $31.6 \pm 15.6$ \\
\hline \hline
\end{tabular}

$88 \mathrm{dBA}$ is equivalent to $200 \%$ or twice the recommended daily dose; Table I).

\section{RESULTS}

Calibration of the SoundMeter app to an external sound meter was set to a standard of within 2-dBA accuracy. Sound level measurements from a random sampling of 17 spin classes are shown in Table II. The average length of exposure was $48.9 \pm 1.2$ minutes, and the average sound level was $100.8 \pm 1.8 \mathrm{dBA}$. In terms of peak noise exposure, the maximum sound level recorded across all classes was $116.7 \mathrm{dBA}$. The calculated average for the maximum sound level of all classes was $113.1 \pm 1.5$ (standard error of the mean) dBA. These peaks were below the NIOSH instantaneous exposure guideline of $140 \mathrm{dBA}$. Graphical depiction of sound levels at 1-minute intervals from one sample class are show in Figure 1. The average sound level of this sample class was $108.0 \mathrm{dBA}$. The sample class shows that sound level variance through the duration of the class was minimal, with high sound intensity for 45 minutes. Moreover, an average of $31.6 \pm 3.8$ minutes was spent at $>100$ dBA per class.

Noise dosimetry data were recorded in 15 of 17 classes. The average length of exposure in this subset of

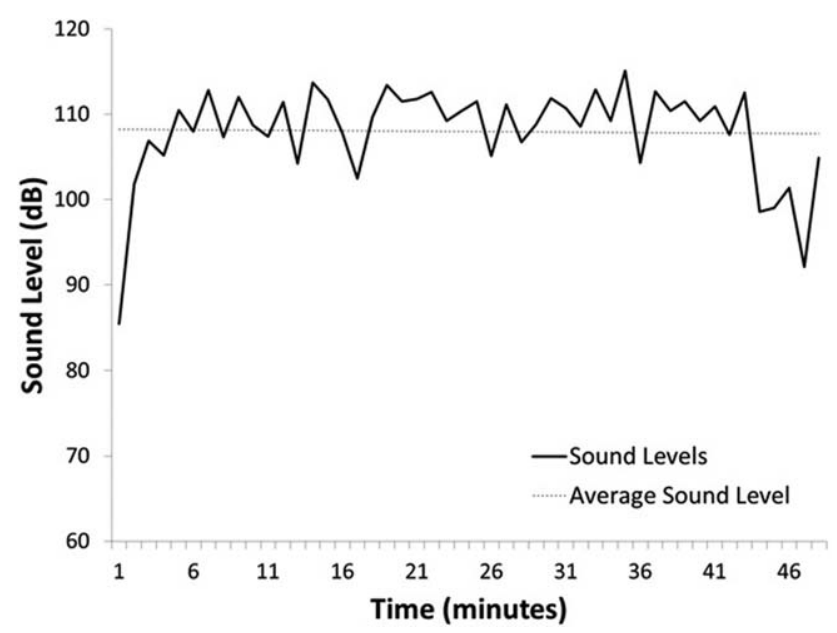

Fig. 1. Sound levels recorded at 1-minute intervals over the duration of one sample class with high noise exposure. Average sound level $=108.0 \mathrm{~dB}$. 
TABLE III.

Summary of Dosimetry Results.

\begin{tabular}{lc}
\hline Measure & Value \\
\hline Number of classes & $15^{*}$ \\
$\begin{array}{l}\text { Average length of noise exposure, min } \\
\text { Average dose during class attended }\end{array}$ & $48.3 \pm 1.2$ \\
$\begin{array}{l}\text { Average projected dose } \\
\quad \text { for 8-hour exposure }\end{array}$ & $895 \% \pm 120 \%$ \\
$\begin{array}{l}\text { Number of classes exceeding } \\
\quad \text { daily recommended dose } \\
\text { in one 45-minute class }\end{array}$ & $8,656 \% \pm 1,143 \%$ \\
\hline
\end{tabular}

\footnotetext{
${ }^{*}$ Two who attended classes did not have dosimetry data due to operato error.

${ }^{\dagger}$ Based on National Institute for Occupational Safety and Health recommend maximum of 8 hours of continuous exposure at $85 \mathrm{~dB}$.

FProjected dose represents cumulative exposure as a percentage of daily recommendation if the class was attended for an 8-hour continuous period.
}

classes was $48.3 \pm 1.2$ minutes. Dosimetry data for these classes are provided in Table III. Overall, 14 of 15 classes exceeded NIOSH recommendations for total daily noise exposure in a single class period. On average, attending one 45-minute spin class was equivalent to $8.95 \pm 1.2$ times the noise exposure recommended for a full 8-hour workday.

\section{DISCUSSION}

Based on preliminary measurements using smartphone-based dosimetry technology, noise exposure in a random sampling of 45-minute indoor stationary cycling classes may put participants and instructors at risk for NIHL. Recordings across several class locations and different franchises showed that high maximum sound levels (average $=113.1 \mathrm{dBA}$ ) may be reached and that the majority of class time was spent at $>100 \mathrm{dBA}$. For individuals who regularly attend spin classes, dosimetry data suggest that in a single 45-minute class, the noise exposure recommended in an 8-hour workday per NIOSH criteria was exceeded in 14 of 15 classes. More specifically, the noise exposure in an average class was $>8$ times the recommended daily value. For individuals with repetitive exposure to the spin class environment, such as instructors, the projected dose for an 8hour workday was nearly $8,700 \%$ of the recommended daily noise level.

Previous studies have also demonstrated that music in fitness classes can reach high levels. One study conducted by Torre and Howell of twelve 50-minute aerobic classes found an average of $87.1 \mathrm{dBA}$ was employed (range $=83.4-90.7 \mathrm{dBA}$ ) and that mean distortion product otoacoustic emissions were lower immediately after class attendance. ${ }^{10}$ Mirbod et al. recorded sound levels of 93 to $96 \mathrm{dBA}$ during peak exercise periods in Japanese aerobics studios and found no significant differences in mean hearing threshold levels after class attendance. ${ }^{11}$ Yaremchuk and Kaczor found that among 125 classes at five American health clubs, $79 \%$ of measurements were $>90 \mathrm{dBA}$ (range $=78-106 \mathrm{dBA}$ ), with participants reporting fluctuating hearing loss and tinnitus after classes $50 \%$ of the time. ${ }^{12}$ In a United Kingdom-based study of aerobics classes, Nassar reported sound levels of 89 to $96 \mathrm{dBA}$, and all subjects had significantly elevated hearing thresholds after classes. ${ }^{7}$ Finally, Beach and Nie studied Australian fitness classes and found that from 2009 to 2011, among several high-intensity exercise classes, cycle or spin classes were the loudest, with an average sound level of 94.0 dBA. ${ }^{6}$ Our findings support this previous work and additionally find that U.S.-based spin classes may actually expose participants to higher sound levels (average $=100.8 \pm 1.8 \mathrm{dBA}$ ) than previously recorded.

This report differs from previous studies in that it is among the first of its kind to use accessible smartphone-based software to assess noise exposure risk from the consumers' perspective. Study results demonstrate that sound exposure may be readily selfmonitored, allowing individuals to become active participants in their hearing health. A host of smartphone apps are available with native calibration, allowing sound level and dosimetry recording. Analogous to personalized health-monitoring apps, such as those included in Apple's HealthKit and FitBit, audiometry apps may allow for real-time monitoring of noise exposure by patients in a wide array of environments that may facilitate hearing loss prevention. The mobile technology used in this report may open the door for preventative hearing health, heretofore largely not practical or feasible, enabling consumer self-monitoring of sound levels and increasing the likelihood of protective measures.

The emergence of boutique fitness classes employing small classrooms with high-intensity workout environments may further increase the likelihood of excessive noise exposure. Previous studies have not quantified the cumulative noise dosimetry risk in this setting. This study finds that using U.S.-based NIOSH criteria, the sound levels exceed occupational health standards. The vulnerability of the auditory system, particularly in the exercise setting, has previously been documented $^{7,10,13}$ and supports the importance of hearing health in spin classes; however, despite the known risks to hearing health, exercise classes have yet to change the intensity of music employed. ${ }^{2}$ As the majority of class time was spent at noise levels $>100 \mathrm{dBA}$, there is a great potential to reduce noise exposure by modulating sound intensity during exercise sessions. Alternatively, individuals can reduce personal noise exposure by employing ear protection. Although these preliminary findings are based on measurements from consumerlevel hardware and software, instructors and participants should be encouraged to undergo routine audiometric testing, as in any setting with potential for noise exposure. Given the standardization of cycling classes across franchises, these data may be applicable nationwide, but such extrapolation would first require reproduction of findings. As hearing health professionals, it is important to understand potential sources of NIHL and counsel patients appropriately.

Although preliminary evidence suggests risk for NIHL in spin classes based on NIOSH criteria, other 
regulatory agencies exist. The Occupational Safety and Health Administration (OSHA) group guidelines for noise exposure maintain an 8-hour limit of $90 \mathrm{dBA}$ with a 5-dBA exchange rate. ${ }^{8,14}$ OSHA guidelines are actionable by law, and when thresholds are exceeded workplaces are required to put in place measures for hearing protection. OSHA guidelines represent industry standards; NIOSH criteria are used to inform OSHA and are based on the best available scientific evidence of exposure risk. In this study, a single class exposure would not exceed OSHA noise exposure standards, but an individual attending consecutive classes, or an instructor teaching multiple classes would exceed the recommended OSHA dose.

Although exercise classes focus on improving overall health and fitness, attendees should be aware of the measurable risk to their hearing health. In addition to the risk of NIHL, damage to the auditory system may predispose consumers to other health risks such as depression or dementia. ${ }^{15,16}$ One prospective study of 639 individuals showed that those with hearing loss were more likely to experience all-cause dementia or Alzheimer disease, with those developing severe hearing loss at the greatest risk. ${ }^{15}$ Thus, attendance of spin classes for cardiovascular health ought to be weighed against the risks associated with hearing damage. Globally, NIHL from occupational exposure is estimated to account for $16 \%$ of all disabling hearing difficulties and contributes approximately 4 million lost disabilityadjusted life years. ${ }^{16}$ In light of this significant impact on overall health, information about excessive noise should be made available to participants. Instructors, who likely experience repetitive noise exposure, should be encouraged to take the necessary precautions to ensure their own hearing health. Because proprietors of fitness centers may not be aware of the potential for NIHL, it may be incumbent upon hearing professionals, participants, and instructors to bring it to their attention. One study found that fitness instructors often overestimate how "motivational" their attendees find loud music and that one-fifth of participants instead found the sound intensity "stressful."

Finally, previous work has investigated the use of smartphones for noise exposure measurements. ${ }^{17-19}$ For example, one recent study comparing smartphone applications to a type 1 sound level measurement system found no significant differences in measurements. ${ }^{17}$ Building on this previous work, our study is among the first of its kind to use accessible smartphone-based software to assess noise exposure risk from the consumers' perspective. Study results demonstrate that sound exposure may be readily self-monitored, allowing individuals to become active participants in their hearing health and increase the likelihood of protective measures. In addition, as the field moves toward personalized medicine and individual health tracking, the methodology implemented in this study highlights one means for patient self-monitoring.

Limitations of this study include the use of native microphones in the mobile devices. These devices were placed in the cupholders of the bikes in spin classrooms.
Given that the location of the microphones was below the average ear level of class participants, these measurements may have been subject to shadowing effects from equipment and may therefore have underestimated noise exposure. Future studies may employ external microphones to allow microphone positioning closer to the ear.

Additionally, the high variance in sound level and dosimetry shows that not all classes are uniformly loud and that data may be location, franchise, or instructor dependent. Class participants were not blinded to the purposes of this study. To mitigate potential bias, all participants were instructed to record each sequential class attended and locate themselves toward the center of the classroom, when possible, based on seat availability. Despite these efforts, nonblinding is a potential source of bias in data collection. In addition, it is conceivable that noise exposure varies throughout the classroom, but for this initial study it was reasonable to use nonsystematically random seat placement for participants. Future studies may inform on exposure risk stratified by participant placement. Sound level variability underscores the importance of personal hearing risk assessment using readily accessible technology.

\section{CONCLUSION}

Participants and instructors may be exposed to high noise levels in cycling classes that exceed recommended limits based on NIOSH guidelines. Use of smartphone technology to assess personal noise exposure risk empowers individuals to appropriately measure noise hazards. As spin classes increase in popularity, these data highlight the importance of monitoring hearing health in the exercise setting.

\section{BIBLIOGRAPHY}

1. Caria M, Tangianu F, Concu A, Crisafulli A, Mameli O. Quantification of Spinning bike performance during a standard 50-minute class. J Sports Sci 2007;25:421-429.

2. Wilsont WJ, Herbstein N. The role of music intensity in aerobics: implications for hearing conservation. J Am Acad Audiol 2003;14:29-38.

3. Vittitow M, Windmill IM, Yates JW, Cunningham DW. Effect of simultaneous exercise and noise exposure (music) on hearing. $J$ Am Acad Audiol 1994;5:343-348.

4. Lindgren F, Axelsson A. The influence of physical exercise on susceptibility to noise-induced temporary threshold shift. Scand Audiol 1988;17:11-17.

5. Kujawa SG, Liberman MC. Adding insult to injury: cochlear nerve degeneration after "temporary" noise-induced hearing loss. J Neurosci 2009; 29:14077-14085.

6. Beach EF, Nie V. Noise levels in fitness classes are still too high: evidence from 1997-1998 and 2009-2011. Arch Environ Occup Health 2014;69: 223-230

7. Nassar G. The human temporary threshold shift after exposure to 60 minutes' noise in an aerobics class. Br J Audiol 2001;35:99-101.

8. Sriwattanatamma P, Breysse P. Comparison of NIOSH noise criteria and OSHA hearing conservation criteria. Am J Ind Med 2000;37:334-338.

9. Niquette PA. Noise exposure: explanation of OSHA and NIOSH safe exposure limits and the importance of noise dosimetry. Can Hear Rep 2012;9:22-29.

10. Torre P, Howell JC. Noise levels during aerobics and the potential effects on distortion product otoacoustic emissions. J Commun Disord 2008;41: 501-511.

11. Mirbod SM, Lanphere C, Fujita S, Komura Y, Inaba R, Iwata H. Noise in aerobic facilities. Ind Health 1994;32:49-55.

12. Yaremchuk KL, Kaczor JC. Noise levels in the health club setting. Ear, Nose Throat J 1999;78:54-57.

13. Alessio HM, Hutchinson KM. Effects of submaximal exercise and noise exposure on hearing loss. Res Q Exerc Sport 1991;62:413-419.

14. Rosenstock L. Criteria for a recommended standard: occupational noise exposure. Natl Inst Occup Saf Heal 1998;1998:1-132. http://scholar. 
google.com/scholar?hl=en\&btnG=Search\&q=intitle:Criteria+for+a+recom mended+standard:+Occupational+noise+exposure\#2.

15. Lin FR, Metter EJ, O'Brien RJ, Resnick SM, Zonderman AB, Ferrucci L. Hearing loss and incident dementia. Arch Neurol 2011;68:214-220.

16. Nelson DI, Nelson RY, Concha-Barrientos M, Fingerhut M. The global burden of occupational noise-induced hearing loss. Am J Ind Med 2005;48: $446-458$
17. Roberts B, Kardous C, Neitzel R. Improving the accuracy of smart devices to measure noise exposure. J Occup Environ Hyg 2016;11:840-846. doi: $10.1080 / 15459624.2016 .1183014$

18. Kardous CA, Shaw PB. Evaluation of smartphone sound measurement applications. J Acoust Soc Am 2014;135:EL186-EL192.

19. Murphy E, King EA. Testing the accuracy of smartphones and sound level meter applications for measuring environmental noise. Appl Acoust 2016;106:16-22. 